\title{
A missed cornual ectopic pregnancy: a case report
}

\section{James K. Prah ${ }^{1 *}$, Leonard Derkyi-Kwarteng ${ }^{2}$}

\author{
${ }^{1}$ University of Cape Coast Hospital, University of Cape Coast, Cape Coast, Ghana \\ ${ }^{2}$ Department of Pathology, School of Medical Sciences, College of Health and Allied Sciences, University of Cape \\ Coast, Cape Coast, Ghana
}

Received: 02 August 2020

Accepted: 03 October 2020

\section{*Correspondence: \\ Dr. James K. Prah, \\ E-mail: james.prah@ucc.edu.gh}

Copyright: (C) the author(s), publisher and licensee Medip Academy. This is an open-access article distributed under the terms of the Creative Commons Attribution Non-Commercial License, which permits unrestricted non-commercial use, distribution, and reproduction in any medium, provided the original work is properly cited.

\begin{abstract}
Ectopic pregnancies continue to be among the leading causes of maternal mortality globally. Cornual pregnancies are types of ectopic pregnancies that occur in the interstitial part of the fallopian tube and invades the uterine wall. We report a case of cornual ectopic pregnancy at 26 weeks that was missed and only diagnosed at autopsy following rupture and death of the pregnant woman. This case emphasizes the importance of a detailed carefully performed ultrasonography in the first trimester for all pregnant women.
\end{abstract}

Keywords: Ectopic, Emergency, Pregnancy, Cornual, Rupture

\section{INTRODUCTION}

An ectopic gestation occurs as a complication of pregnancy when the embryo gets implanted outside the uterus. ${ }^{1}$ Globally, it is the leading cause of maternal mortality in the first trimester. ${ }^{2}$ Even though cornual pregnancies are rare forms of ectopic pregnancies, they carry very significant risks for morbidity and mortality. ${ }^{3}$ Whilst about $90 \%$ of ectopic pregnancies are diagnosed unruptured in developed countries, diagnosis before rupture is uncommon in developing countries. ${ }^{4}$ In this report, we tell the story of an antenatal clinic attendant whose cornual ectopic pregnancy was only diagnosed at autopsy. The aim of this report is to highlight the need for clinicians to increase their suspicion about cornual ectopic gestations even as late as 26 weeks of gestation and for a more careful ultrasonography in the first trimester of pregnancy to accurately localize all pregnancies.

\section{CASE REPORT}

A 26-year old mother (G2, P1), delivered through a caesarean section two years before presentation. She was rushed to the emergency unit of the University of Cape Coast Hospital having collapsed at home. She was found to have died upon arrival by the attending physician.

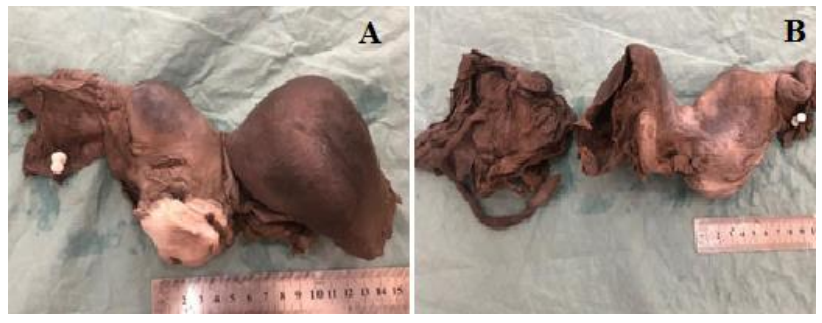

Figure 1: (A) Uterus with adnexa; (B) uterus with placenta.

She first reported for antenatal clinic at 18 weeks. A pelvic scan was performed at that gestation and a single viable intrauterine fetus with no abnormality was reported. She subsequently had two more antenatal visits. According to her close relatives, three days before presentation she complained of severe lower abdominal pains and bleeding per vaginam. She was given some pain relief at home with the plan to visit the hospital if 
condition got worse. Her condition got worse and later collapsed at home.

Autopsy findings were massive haemoperitoneum, ruptured left cornual gestation, and a dead male fetus (660 g). The maternal mortality was therefore caused by haemorrhagic shock secondary to ruptured cornual gestation (Figure 1).

\section{DISCUSSION}

A maternal death is the death of a woman while carrying a pregnancy or within 42 days of terminating a pregnancy, irrespective of how long the pregnancy lasted and site of the pregnancy. ${ }^{5}$ It may arise from any cause related to or aggravated by the pregnancy or its management but not from accidental or incidental causes. ${ }^{5}$ Ghana has a high maternal mortality ratio (MMR) of 310 deaths per 100,000 live births. In the coastal zone of Ghana that includes cape coast, the MMR is about 336 per 100,000 live births. ${ }^{6}$ Maternal deaths are usually from direct or indirect causes. Direct maternal deaths are deaths resulting from obstetric complications of the pregnancy, from interventions, omissions, incorrect management, or from a chain of events resulting from any of the above situations. Indirect maternal deaths are usually from pre-existing disease or from a disease that developed during the pregnancy which was not due to a direct obstetric cause, but was aggravated by the physiologic effects of the pregnancy. In this report, the pregnant woman had died from ectopic gestation, a direct cause of maternal mortality. An earlier study conducted in Ghana found the top five causes of maternal death to be: haemorrhage $(21.8 \%)$, abortion $(20.7 \%)$, hypertensive disorders (19.4\%), infections $(9.1 \%)$ and ectopic gestation $(8.7 \%){ }^{7}$ Ectopic pregnancy continues to be a condition of immense gynecological and obstetric importance, particularly in the developing world, because of the high morbidity and mortality associated with it. It is the leading cause of death among pregnant women in the first trimester and accounts for $10 \%-15 \%$ of all maternal deaths. ${ }^{2}$ In developing countries, majority of patients present late with rupture and hemodynamic compromise making ectopic pregnancy an important cause of maternal morbidity and mortality. ${ }^{8}$ In this case report, the woman reported late after probably rupturing for some days evidenced by the onset of severe lower abdominal pains. It is also a cause of fetal wastage and has been associated with recurrence and impairment of subsequent fertility. ${ }^{9}$

More than $95 \%$ of ectopic pregnancies occur in the fallopian tube, making this the commonest site. ${ }^{10}$ In a Nigerian study, the commonest site of ectopic gestation was the ampullary region, followed by the isthmus, fimbriae, cornual and tubo-ovarian regions. ${ }^{11}$ In this report, autopsy revealed a cornual pregnancy. A cornual pregnancy is an ectopic pregnancy that develops in the interstitial portion of the fallopian tube and usually invades through the uterine wall. Only 2 to $3 \%$ of all tubal pregnancies are either interstitial or cornual, making cornual ectopic pregnancies rare. ${ }^{12}$ Most ectopic gestations rupture between 8 and 12 weeks following pregnnancy. ${ }^{11}$ Cornual pregnancies often rupture later than other tubal pregnancies because the myometrium is more distensible than the fallopian tube, this therefore allows more room for fetal growth before rupture. This may explain why in this case the pregnancy travelled for 26 weeks.

Clinical symptoms of ectopic pregnancy frequently appear 6 to 8 weeks after the last normal menstrual period. However, clinical manifestations can develop later if the pregnancy is not localized in the fallopian tube. In this study the patient complained of severe lower abdominal pains and bleeding per vaginam when she was about 25 weeks. This is certainly a very late presentation. When the fertilized ovum is implanted well within the cornual/interstitial portion, rupture usually do not occur until 14 to 16 weeks, often with severe hemorrhage and associated mortality. ${ }^{13}$ In a study including 1800 ectopic pregnancy cases, almost one third of cornual ectopic pregnancies were diagnosed after rupture and accompanied with significant hemoperitoneum related to the advanced gestational age. ${ }^{1}$ In our case the patient suffered a massive haemorrhage and died as a result. Diagnosis was only made at autopsy.

Interstitial and cornual pregnancies have a mortality rate of $2-2.5 \%$ and this accounts for $20 \%$ of all deaths due to ectopic pregnancies. ${ }^{3,14}$ Early diagnosis of interstitial/cornual pregnancy before the uterine ruptures is difficult. Due to their relative rarity and potential initially confusing clinical and radiologic presentation, cornual ectopics may pose a problematic diagnosis for both the physician and radiologist.

\section{CONCLUSION}

Our study has shown that cornual gestations could be carried into the third trimester before rupture. It is important to enhance the clinician's suspicion about cornual pregnancy. Thus, more detailed examination by transvaginal ultrasonography may contribute to accurate localization and early diagnosis of cornual pregnancies to avert the occurrence of this case of missed cause of maternal mortality.

\section{Recommendations}

All pregnant women should be encouraged to take first trimester scans to allow for early location of pregnancies. When ultrasound scans are being performed in the first trimester, every effort must be made by radiologists and radiographers to accurately determine the location of the pregnancy. In our case, even though a scan was performed, it was done late and probably all the attention was on the parameters of the fetus and not where it was located. 
Funding: No funding sources

Conflict of interest: None declared

Ethical approval: Not required

\section{REFERENCES}

1. Bouyer J, Coste J, Fernandez H, Pouly J, Job-Spira N. Sites of ectopic pregnancy: a 10-year populationbased study of 1800 cases. Hum Reprod 2002;17(12):3224-30.

2. Sara HG, Uzelac PS. Early pregnancy risks. In: DeCherney AH, Nathan L, Goodwin MT, Laufer N, editors. Current Diagnosis and Treatment: Obstetrics and Gynecology. 10th ed. Columbus (OH): McGraw-Hill. 2007;259-72.

3. Molinaro T, Barnhart K. Ectopic pregnancies in unusual locations. Semin Reprod Med. 2007;25(2):123-30.

4. Nkyekyer K. Ectopic pregnancy in Ghana-time for change. Ghan Medic J. 2006;40(1):1-2.

5. World Health Organization. Maternal Mortality in 2000: Estimates by WHO: UNICEF, UNFPA. Geneva, Switzerland: WHO: 2004. Available at: http://www.childinfo.org/files/maternal_mortality_in _2000.pdf. Accessed on 12 June 2020.

6. Ghana Statistical Service (GSS), Ghana Health Service (GHS), and ICF. 2018. Ghana Maternal Health Survey 2017: Key Findings. Rockville, Maryland, USA: GSS, GHS, and ICF.

7. Der EM, Moyer C, Gyasi RK, Akosa AB, Tettey Y, Akakpo PK, et al. Pregnancy related causes of deaths in Ghana: A 5-year retrospective study. Gha Medic J. 2013;47(4).

8. Panti A, Ikechukwu NE, lukman OO, Yakubu A, Egondu SC, Tanko BA. Ectopic pregnancy at Usmanu Danfodiyo University Teaching Hospital Sokoto: a ten-year review. Ann Niger Med. 2012;6(2):87-91.

9. Abdul FI. Ectopic pregnancy in Ilorin: a review of 278 cases. Niger J Med. 2000;9(3):92-6.

10. Erickson BT. Ectopic pregnancy. In: Bader T, editor. Ob/Gyn Secrets. 3rd ed. Maryland Heights (MO): Mosby 2007;109-13.

11. Lawani Osaheni, Anozie Okechukwu B, Ezeonu PO. Ectopic pregnancy: a life-threatening gynecological emergency. Int J Wom Heal. 2013;5

12. Malinowski A, Bates S. Semantics and pitfalls in the diagnosis of cornual/ interstitial pregnancy. Fertil Steril. 2006;86(6):1764.e11-4.

13. Soriano D, Vicus D, Mashiach R, Schiff E, Seidman D, Goldenberg M. Laparoscopic treatment of cornual pregnancy: a series of 20 consecutive cases. Fertil Steril. 2008;90(3):839-43.

14. Tang A, Baartz D, Khoo S. A medical management of interstitial ectopic pregnancy: a 5-year clinical study. Aust N Z J Obstet Gynaecol. 2006;46(2):10711 .

Cite this article as: Prah JK, Derkyi-Kwarteng L. A missed cornual ectopic pregnancy: a case report. Int J Reprod Contracept Obstet Gynecol 2020;9:4695-7. 